\title{
Abraham Kuyper en Marie du Toit oor vrouestemreg
}

\author{
C. Landman \\ Departement Kerkgeskiedenis \\ Universiteit van Suid-Afrika \\ PRETORIA
}

\begin{abstract}
In the period between 1914 and 1921 three texts concerning Afrikaans women were published on women's suffrage: these texts were written by Abraham Kuyper (1914); a commission of the Synod of the Gereformeerde Kerke of South Africa with J.D. du Toit as a member of this commission (1920); and by J.D. du Toit's sister, Marie du Toil (I92I). In this article these three texts are compared as to their contents. It is indicated that

- Kuyper's views against women's vote were taken over directly by the commussion of the GKSA. The views of both Kuyper and the commission were strongly rejected by Marie du Toit in the light of her understanding of being both reformed and female.
\end{abstract}

\section{Inleiding}

\subsection{Liberale Nederland en Afrikaanse vrouens}

In 1894 is die "Vereeniging voor Vrouwenkiesrecht" in Nederland gestig. Gedurende die eeuwisseling en vroeè twintigste eeu beywer liberale vrouens in $\mathrm{Ne}$ derland hulle vir vrouestemreg, en verkry dit ook in 1918 (Naber, 1937). Hierdie beweging vir vrouestemreg in Nederland het min effek op die Afrikaanse vrouens in Suid-Afrika gehad (kyk Stockenström, 1944). Gedurende die eeuwisseling het die noordelike Afrikaanse vrouens hulle in Britse konsentrasiekampe bevind, en daarna het hulle deelgeneem aan die herstel van die gesinslewe nadat die oorloë met Engeland in 1902 ten einde geloop het. Engelse vrouens in Suid-Afrika het wel in 1911 die "Women's Enfranchisement Association of the Union" gestig (Walker, 1990), maar na 1910 het die Afrikaanse vrouens aktief deelgeneem aan die simbolisering van hulle rol as volksınoeder met die inwyding van die Vrouemonument as hoogtepunt. Rondom hierdie inwyding het die vrouens geld ingesamel vir die skryf van hulle geskiedenis. Hierdie geskiedenis met die titel Die boervrouw, moeder van haar volk (1918) is dan ook deur Willem Postma onder die skuilnaam $d r$. $O^{\prime} K u$ ulis geskryf. Drie jaar later verskyn Eric Stocken- 
strom se Die vrou in die geskiedenis van die Hollands-Afrikaanse volk (1921). In hierdie werke word, via 'n spesifieke siening van die verlede, vrouens se rol binne die volk en gesin beperk en vasgelê (Brink, 1990). ' $n$ Goeie 'Boervrou' is onderdanig, saggeaard, kuis en spaarsamig. Haar rol in die gesin en volk is ondersteunend, 'n rol waarvoor sy haar indiwidualisme moet aflê. Haar geskiedenis, beweer Postma (1918:100), is die geskiedenis van iemand wat teen heidene, swartes en Engelse geveg het ter wille van die behoud van haar volk en haar godsdiens; dit is nie die geskiedenis van iemand wat die Europese vrouens se sug na stemreg navolg nie.

\subsection{Liberale Nederland en Abraham Kuyper}

In reaksie teen "de toonaangevende Liberale kringen" (Kuyper, 1914:7) in Nederland wat reeds na 1910 vrouestemreg in beginsel aanvaar het, bundel Abraham Kuyper ' $n$ aantal artikels wat in die Standaard verskyn het (De Bruijn, 1987:314,315) en gee dit in 1914 uit onder die titel De eerepositie der vrouw. Hy voer daarin aan dat dit onnatuurlik vir vrouens is om 'n indiwiduele stem uit te bring terwyl die natuurlike gesinshoof dit namens die gesin doen. Terwyl die Nederlandse liberale rigting vir vrouestemreg weinig invloed op Afrikaanse vrouens in Suid-Afrika gehad het, het die anti-rewolusionêre denke van Abraham Kuyper (1837-1920 - en sy voorganger Groen van Prinsterer, 1801-1876) diepgaande invloed op die Afrikaanse mans van Suid-Afrika uitgeoefen (soos hierdie artikel in die geval van die godsdienstige leiers van die Gereformeerde Kerke in Suid-Afrika sal aandui).

Kuyper is natuurlik deur verskeie vooraanstaande Nederlandse teoloë ondersteun in sy reaksie teen politieke feminisme. So het W. Geesink, wat vanaf 1890 tot 1926 professor in Etiek aan die VU was, in sy handboeke oor die etiek die konserwatiewe siening dat vrouens nie aan mans gelyk is nie, verdedig (Manenschijn, 1987:20-22). H. Bavink het hom by hierdie siening aangesluit, alhoewel sy De vrouw in de hedendaagsche maatschappij, wat verskyn het net nadat die Nederlandse vrouens in 1918 stemreg verkry het, tog in die rigting beweeg om vrouens se openbare rol te erken en teologies te regverdig (Gerritsma, 1987:7983). In die huidige artikel word slegs na die werk van Abraham Kuyper verwys, omdat dit die uitsluitlike bron vir die GKSA se besluit teen vrouestemreg was.

\subsection{Die Gereformeerde Kerke in Suid-Afrika en Abraham Kuyper}

In Suid-Afrika maak 'n kommissie van die Sinode van die Gereformeerde Kerke in 1920 ' $n$ aanbeveling oor vrouestemreg in sewe punte (Handelinge van die Sinode van die Gereformeerde Kerke, 1920:81-82). Op die Sinodesitting van 1920 word die kommissie se advies aanvaar en die Sinode besluit "om altyd te 
protesteer teen Vroue Stemreg op grond van Gods Woord" (Handelinge, 1920: 37). Die Sinode beveel dan ook hulle besluit teen vrouestemreg in die kerk by die Parlement aan as 'n protes teen moontlike vrouestemreg bimne die breëre politiek. Een van die lede van die genoemde kommissie wat vrouestemreg afgekeur het, was J.D. du Toit, die bekende digter Totius. Die invloed wat Abraham Kuyper op J.D. du Toit, sowel as op sy vader, S J. du Toit, uitgeoefen het, word in verskeie werke aangetoon, veral dié van D'Assonville (1977) en Brown (1992).

\subsection{Marie du Toit, die GKSA en Abraham Kuyper}

'n Enkele stem van protes teen hierdie kommissie se aanbeveling kom dan inderdaad uit die familiegeledere van S.J. du Toit. In 1921, die jaar na die genoemde Sinodesitting, publiseer Totius se suster, Marie du Toit, 'n boek ten gunste van vrouestemreg onder die titel l'rou en feminist, of lets oor die vrouevraagstuk. Maria Magdalena du Toit is in 1880 as die jongste kind uit S.J du Toit se eerste huwelik gebore. Sy was 50 jaar ond toe sy in 1931 in haar broer, Totius, se huis op Potclefstroom aan tuberkulose gesterf het (Sterfkennisgewing, Transvaalse Argief). Sy was ongetroud en het al haar besittings aan haar broer nagelaat (Testament, Transvaalse Argief).

Marie du Toit se betoog vir vrouestemreg in die kerk en vir die parlement is uniek bimne haar konteks. Sy was nie deel van 'n vrouebeweging nie en verwyt Afrikaanse vrouens vir hulle belangeloosheid in hierdie verband (Du Toit, 1921:24 e.v.). Du Toit verwerp in haar boek die heersende opvatting onder Afrikaanssprekendes oor die onwenslikheid van die openbare rol van vrouens in die kerk en die politiek (Herald, 1981-09-11); daannee saam kritiseer sy implisiet die invloed wat Abraham Kuyper op haar pa en broer uitgeoefen het. In haar goedgedokumenteerde boek noem Du Toit nie die naam van Abraham Kuyper nie, haar reaksie teen sy denkbeelde is egter duidelik uit haar bedekte verwysings na sy boek - soos waar sy haar skok uitspreek oor die feit dat wanneer 'n vrou 'n man se besitting te noem, dit as haar "ere-posiesie" gesien word (Du Toit, 1921: 39).

Marie du Toit was nie 'n beleidmaker gedurende haar lewe nie en sy is na haar dood gou vergeet. In 'n radiopraatjie oor Vrouerubrick onder die opskrif "Vrouens rondom Totius" (1977) word daar weer 'n enkele keer na haar verwys. (Hierdie radiopraatjie is gepubliseer in die Herald, 11 September 1981; Brink, 1990.) Marie du Toit se siening oor vrouestemreg het nie direk daartoe gelei dat die Gereformeerde Kerke van Suid-Afrika in 1988 aan vrouens die stemreg toegestaan het nie. Tog was sy in haar sosiale denke haar tyd vooruit en is haar idees oor die openbaarmaking van die lyding wat sosiale en kerklike beperkings op vrouens teweegbring, en haar verwerping van die konsep van die 'natuurlike vrou' van belang vir die huidige gesprek oor die toelating van vrouens tot die besondere ampte in die Gereformeerde Kerke in Suid-Afrika. 


\subsection{Doelstelling: Die 'gesprek' tussen Kuyper, die GKSA en Marie du Toit}

Hierdie artikel word toegespits op Marie du Toit se reaksie op die sewe punte wat in 1920 deur die Gereformeerde Kerke in Suid-Afrika teen vrouestemreg aanvaar is. Daar word gesuggereer dat Abraham Kuyper hierdie standpunte sterk beînvloed het en daar sal op inhoudelike ooreenkomste tussen die sewe punte en die inhoud van sy boek, De eerepositie der vrouw (1914), gewys word. Verwysings na Kuyper sal feitlik uitsluitlik ten opsigte van hierdie werk van hom wees: in sekondêre bronne oor Kuyper se sosiale bewussyn, soos byvoorbeeld in Smeenk (1937) en Van Weringh (1967), word daar nie na sy opvatting oor vrouens se openbare rol verwys nie. Marie du Toit se kritiek op hierdie standpunte, en dan veral haar sosiale denke, sal, weens die huidige belang van haar opvattings, in die sentrum van die bespreking staan.

Die drie tekste word nie beoordeel vanuit die ideologiese veronderstellings van die skryfster van hierdie artikel nie. Die tekste word naas mekaar geplaas en daar word gekonsentreer op die reaksie van die een teks op die ander en hoe hulle vir mekaar as interteks optree.

\section{Vrouens se mindere posisie is 'n posisie van eer}

Die eerste punt van die kommissie van die GKSA se aanbeveling by die sinode teen vrouestemreg, lees soos volg:

Die uitvoering van stemreg is ' $n$ regeeraksie en kom as sodanig aan die man as hoof van die gesin toe (1 Tim. 2:12, 1 Kor. 11:3, Tit. 2:5), en nie aan die vrou nie, wat blykens die skeppingsverhaal die man tot ' $\mathrm{r}$ hulp bygestel is (Gen. 2:18). Hieruit blyk dat deur Gods bestel die vrou in ' $n$ mindere posisie geplaas is, maar dit sluit nie in minderwaardigheid van persoon nie; want daar staan selfs geskrewe dat die mens vader en moeder sal verlaat en sy vrou sal aanhang (Gen. 2:24, Matt. 19:5). (Handelinge van die Sinode, 1920:81).

Ter verdediging van gesinshoofstemreg, stel Abraham Kuyper in sy boek De eerepositie der vrouw (1914:48) die vraag "Welke is nu de positie, die door God zelf, blijkens die Schrift, aan de vrouw is aangewezen?", en antwoord dit vanuit die skeppingsverhaal van Genesis 2. Volgens Kuyper verduidelik Genesis 2 (vers 18) aan die een kant dat die vrou as ' $n$ hulp gemaak is, en aan die ander kant (vers 24) dat hierdie mindere posisie ' $n$ ereposisie is omdat die man sy ouers verlaat om die vrou, as die middelpunt van die nuwe gesin, aan te hang.

Dieselfde Skrifgedeeltes word aangehaal om die kommissie van die GKSA se tweevoudige siening van vrouens se Skriftuurlike posisie ten opsigte van die 
openbare lewe te verwoord: vrouens is minder as mans in die openbare lewe en Genesis 2:18 impliseer dat 'n 'hulp' nie kan regeer nie; aan die ander kant plaas Genesis 2:24 vrouens in 'n ereposisie binne die huisgesin.

Volgens Du Toit (1921:139), wat die onderskeid tussen openbare en private lewensruimtes verwerp, staan bostaande interpretasies van Genesis 2:18 en Genesis 2:24 in spanning met mekaar: 'n persoon wat as ' $n$ 'hulp' gesien word, word in ' $n$ minderwaardige en nie in 'n ereposisie geplaas nie. Om ' $n$ minderwaardige posisie 'n ereposisie te noem, is neerbuigend en paternalisties, vind sy. Volgens Du Toit (1921:12) kan mans nie alleen oor vrouestemreg besluit nie; dit is ' $n$ besluit wat eintlik by vrouens berus. Sy vergelyk propaganda teen vrouestemreg met argumente wat teen die vrystelling van slawe geopper is:

(D)it is so opvallend dat die beskouinge en verontskuldiginge altyd van die baas se kant gesien is: hoe goed hy die slaaf behandel; hy bevestig hoe tevrede die slaaf is, dat hy die slaaf van al die nodige voorsien, ens. Maar ... die vernaamste is tog: hoe voel die slaaf daaromtrent?

Sy nooi mans derhalwe uit om hulle in die plek van vrouens te stel en die lyding te ervaar wat vouens se onnatuurlike minderwaardigheid teweegbring.

\section{Die natuurlike vrou}

Die tweede punt van die kommissie se verslag omskryf 'mindere posisie' in terme van andersoortigheid:

Die mindere posisie vloei voort uit die andersoortigheid van wese en aard deur God aan haar toebedeel. Met die woorde van Gen.1:27 sê Jesus dat Hy wat die mens gemaak het, hulle gemaak het man en vrou (Matt. 19:4). Dis dus nie volgens die 'sagmoedige en stille gees' van 'n vrou, wat kostelik is voor God (1 Pet. 3:4), om sig naar buite te laat gelde in die woelinge van publieke lewe nie. Haar roeping lê hoofsakelik op die terrein van die gesinslewe, waartoe God haar besondere gawe en talente bestem het (Spr. 31:10-31). (Handelinge van die Sinode, 1920:81).

Kuyper baseer sy skeiding tussen vrouens se openbare optrede, wat hy afkeur, en hulle privaatregtelike posisie, waarbinne hy hulle bevryding voorstaan, op twee argumente: eerstens is vrouens se deelname aan die politiek teen die wil van God, en tweedens is dit teen die natuur van vrouens. Die wil van God oor vrouens en die politiek lees Kuyper af uit Spreuke 31:10-31 waarin die ideale huisvrou geteken word, 'n vrou wat nie "in die poorte sit" nie (Kuyper, 1914:51). Die natuurlike vrou se eienskappe lei Kuyper af uit sy siening van die ideale huwelik en hierdie eienskap kom volgens hom ooreen met hoe God die vrou oorspronklik geskep en verorden het dat sy moes wees (Kuyper, 1914:36): die natuurlike vrou is skaam (1914:34); sy is passief (1914:35); haar beendere is swakker en al- 
hoewel sy skerper as die man kan gil, is haar motoriese stelsel minder ontwikkel (1914:37); terwyl die man se sterkte in sy kop en ribbekas lê, lê dit by die vrou onder haar middel (1914:38); daar is ook min "scherpzinnig ontwikkelde verstandsvrouwen" (1914:38). Kuyper (1914:27) erken egter ook sy vrees vir die moontlike oorheersing van vrouens op politieke gebied as hulle die stemreg sou kry: gedurende sy tyd was daar ongeveer 28,000 meer vrouens as mans in Nederland. Kuyper sê dat hy nie daarvoor kans sien dat die kabinet in duie stort elke keer as die broodprys met 'n sent opgaan nie.

Die genoemde kommissie van die sinode van die GKSA lei, in navolging van Kuyper, ook God se wil oor vrouens se huishoudelike posisie uit Spreuke 31:1031 af. Ook hierdie kommissie omskryf hulle siening van die natuurlike vrou in Bybelse terme: die natuurlike vrou is sagsinnig, stil en geroep tot die gesinslewe.

Teen hierdie argumente oor die natuurlike vrou spreek Du Toit haar sterk uit. Sy voel weer eens 'n spanning aan tussen wat as 'Bybels' (Christelik-Gereformeerd) en wat as 'natuurlik' deur die betrokke mans beskrywe word. Die leer van 'die natuurlike vrou' is immers vreemd binne die opdrag van die Calvinisme dat ons die natuurlike mens moet aflê. Du Toit (1921:55-62) voer aan dat die verskille tussen die geslagte nie groot is nie en dat die verskille eerder sosiaal as 'natuurlik' of aangebore is; vrouens verskil immers ook van mekaar. Sy voer aan dat argumente oor 'n vrou se 'natuur' gebruik word om die meeste beroepe vir mans te reserveer en vrouens op grond van hulle (swakker) natuur uit te sluit (1921:19). Sy antwoord op argumente wat op die vrou se 'natuur' berus deur, onder andere, na Kant se uitspraak te verwys dat vrouens nooit meetkunde sal leer nie, en dit te opponeer met lyste van vrouens wat wel intellektueel presteer het en nie die uitsondering was nie (1921:66).

Du Toit (1921:20) deel egter nie Kuyper se vrees dat vrouens deur stemreg die openbare lewe sal oorheers nie. Sy betreur, inteendeel, die feit dat vrouens onverskillig teenoor die politiek staan en hoegenaamd nie lojaal teenoor mekaar is nie. Sy wyt dit aan die feit dat vrouens 'n slegte selfbeeld het, nie glo dat daar iets groots uit hulleself na vore kan kom nie en bedreig voel as ander vrouens wel tot iets groots kom. Du Toit self (1921:118) glo dat 'n sintese van vrouens se private en openbare rolle ' $n$ gelukkige ontwikkeling sal wees en haal daarvoor Jan Smuts aan wat sou gesê het dat vrouens se insig in sosiale kwessies openbaar gemaak moet word deur vrouens aan die politiek te laat deelneem en veral deur hulle insigte by (sosiale) wetgewing te laat geld.

\section{Vrouens is nie indiwidue nie}

Die derde punt van die kommissie van die GKSA stel indiwidualisme teenoor die skeppingsordinansie van die Woord van God: 
Die beweging vir vroue-stemreg vloei nie voort uit die beginsels van Gods Woord nie, wat uitgaan van die organiese verband waarin God die mensheid geskape het en waaruit sowel die staatkundige as kerkelike saamlewe opgebou word. Die huisgesin, die vername sel of kiem waarvan die skepping uitgaan, is vir die drywers van vroue-stemreg nie die beginpunt nie, maar wel die individu of enkele persoon. Hierdie individualisme vat die mens nie in sy organiese skeppings-verband nie, maar as losse persoonlikheid, met 'n vrye wil, los en onafhankelik van alle goddelike bestel. As sodanig tree dan die vrou nie op volgens haar skeppingsordonnansie nie, maar as persoon naas en in gelyke posiesie met die man. Dis die leer van die Franse Rewolusie, wat die mensheid nie erken in sy organiese opbou nie, maar as 'n klomp losse eenlinge. Daarom is hulle ten opsigte van die staatkunde ' $n$ losse hoop kiesers toevallig op 'n stuk grond saamgegaar (Handelinge van die Sinode, 1920:81).

Kuyper (1914:23) skets drie situasies wat hy as die oorsake van vrouens se sug na stemreg sien:

* die valse indiwidualisıne van die Franse Rewolusie;

* die opdringerigheid van die Anglosaksiese suffragette; en

* die toenemende aantal vrouens wat ongetroud bly.

Genoemde kommissie van die GKSA neem, in navolging van Kuyper, hierdie drie sake vervolgens in behandeling in drie punte: punt 3 behandel die Franse Rewolusie se invloed op vrouens, punt 4 die Anglosaksiese invloed, en punt 7 die probleem van ongetroude vrouens se bydrae tot die samelewing.

Op die standpunt dat vrouens die organiese skeppingsorde verwerp en onwetend onder invloed van die indiwidualisme van die Franse Rewolusie staan, gee Du Toit (1921:75) 'n eenvoudige antwoord: sy het nie nodig om die Franse Rewolusie na te volg nie; sy hoef maar net om haar na die lyding te kyk wat vrouens ondergaan as gevolg van hulle gebrek aan 'n openbare stem. Sy praat nie die Rewolusie na nie; sy sê maar net wat in haar hart is. Rewolusionêre idees is nie by haar gekweek nie, haar eie lewe en die omstandighede van die vrouens om haar het dit in haar gekweek. As daar een ding is, wat 'natuurlik' is omtrent vrouens, dan is dit hulle meegevoel met lydendes, selfs oor die kleurskeidslyn heen, beweer sy. Du Toit (1921:75) haal in hierdie verband 'n voorval aan wat deur Olive Schreiner beskryf is en waarin verwys word na die geniale sosiale insigte van ' $n$ swart vrou:

'n Ander treffende voorbeeld van ons natuurlike gevoelens omtrent die posiesie van ' $n$ vrou, is die mededeling van Olive Schreiner omtrent haar gesprek met 'n kaffermeid oor die saak toe sy (Olive) agtien jaar oud was elkeen kan dus uitreken hoe lang gelede dit was. Sy sê omtrent die inboorling dat sy aan haar nie anders kan dink as aan 'n sjenie. Sy het in haar primitieve toestand reeds die hele saak oorweeg en het op die skryfster 'n blywende indruk gemaak deur 'n pragtige en gevoelvolle taal te skilder die 
posiesie van 'n vrou van haar ras - die hele storie van begin tot en met al die lyde wat beperkings, veelwywery en ondergeskiktheid meegebring het. Die skryfster sê met nadruk dat sy nog nooit weer 'n kragtiger en meer betekenisvolle ontboeseming oor vrouelyde aangehoor het nie. Wel, en hoe rym dit nou met die beskuldiging wat ons deur landgenote toegewerp word van agter nuwe idees te loop of vir die soort van ding gekweek te word?

Du Toit se ontkenning van rewolusionêre invloed en haar beklemtoning dat sy slegs onder invloed van haar konteks staan, vat sy soos volg saam: "Jy behoef nie te loop agter wat in jou eie siel en lewe sit nie, en jy behoef nie te kweek wat jou hart van vol is nie!" (Du Toit, 1921:76) Vrouens is nie opgesweep tot indiwidualisme en 'n onchristelike sug na die openbare lewe nie; vrouens wil die nood onder mekaar in behandeling neem, is Du Toit se standpunt.

\section{Vrouens is beïnvloedbaar}

Punt 4 van die kommissie van die GKSA beweer verder dat vrouestemreg uitheems aan die Christelike aard van die Afrikaanse volkslewe is:

Ten opsigte van Suidafrika is dus vrouestemreg 'n uitheemse plant, wat veral in anglosaksiese lande (Engeland, N. Amerika, Australië en NuwSeeland), en onder sosialistiese invloed voortgewoeker het. Van dié uitheemse invloede het die Afrikaanse volkslewe, uit krag van sy Christelikhistoriese aard, sig nog altyd vrygehou, en die teenwoordige beweging skyn dié van nuwigheid aan die Afrikaanse vrou met geweld te opdring (Handelinge van die Sinode, 1920:81).

Die kommissie van die GKSA sluit op hierdie punt aan by die tweede oorsaak wat Kuyper vir vrouens se onchristelike strewe na stemreg aangee. Die kommissie is van mening dat die Anglosaksiese stemregbeweging vreemd aan die Afrikaanse volkseie is en veral vreemd aan die Christelike volkseie van die Afrikaners is.

Opmerklik in hierdie verband is die verskillende maniere waarop Kuyper en Du Toit dieselfde Anglosaksiese vrouens histories voorstel. Volgens Kuyper (1914:13) is "de Anglosaksische vrouw" (soos byvoorbeeld Mary Wallstonecraft) iemand met 'n oorontwikkelde persoonlike wil wat hierdie wil op almal afdwing. "De Anglosaksische vrouw" manipuleer selfs filosowe en staatsmanne om haar idees te verkondig. Du Toit (1921:110-111), daarenteen, beskryf Mary Wollstonecraft se boek Vindication of the Rights of Woman as een van die moedigste ondernemings van haar tyd (einde agtiende eeu). Sy teken Wollstonecraft juis as 'n vrou wat geprotesteer het teen die beeld van vrouens wat deur een van die voorstanders van die Franse Rewolusie, Jean Jacques Rosseau, voorgehou is. 
Hierdie voorbeeld beklemtoon hoe Kuyper en Du Toit se verskillende sieninge van vrouens hulle historiese voorstellings van vrouens beinvloed. Omdat Kuyper glo dat alle vrouens dieselfde natuur het, stel hy vrouens binne tipes voor. Vrouens word binne slegs twee tipes geteken: Christelike vrouens wat volgens die Bybel in organiese verbande lewe, en rewolusionêre vrouens wat deur die Franse Rewolusie en die Anglosaksiese vrouens op die dwaalspoor van idealisme gebring is. Kuyper staan een standaardtipe vrou voor soos wat hy glo die samelewing en God vereis, en laat daarbinne nie ruimte vir vrouens om hulleself te defmieer nie.

Du Toit, daarenteen, neem die kans waar om haarself as vrou te omskryf. Wanneer sy ander vrouens histories plaas, teken sy hulle binne hulle kontekste as lewende persone wat onder verskillende, en ook dieselfde, omstandighede van mekaar verskil het.

\section{Vrouens se ereplek}

In punt vyf van die kommissie van die GKSA word vrouens se ereplek in die huisgesin beskryf:

Daar egter die politiek, veral die partypolitiek soms met grofheid en hartstogtelikheid gepaard gaan, mag die vrou as 'swakkere vat' daaraan nie opgeoffer word nie. Wanneer haar ereplek in die huisgesin op die politieke terrein verskuif word, moet sy in oneer geraak, omdat sy daar, vanwege haar ingeskape, ander geaardheid nooit met die man, as die sterkere, kan meeding nie (Handelinge van die Sinode, 1920:82).

Dat Du Toit die mindere posisie wat aan vrouens binne die gesin toegesê word, nie as 'n ereplek sien nie, maar as 'n "pakkameel-ereposiesie" (Du Toit, 1921:139) wat vrouens al die werk laat doen sonder dat hulle inspraak in die ordening van die samelewing kry, is reeds bespreek. Die betrokke kommissie van die GKSA laat egter uit hulle fonmulering van punt 5 blyk dat 'n ereplek aan vrouens toegeken word om hulle van mededinging met mans te weerhou en sluit daarby by Kuyper se vrese aan oor die moontlike openbare oorheersing van vrouens in magsposisies.

Kuyper (1914:15-16) beweer dat mans vrouens beheers as reaksie op vrouens se magspel. Du Toit (1921:9 e.v.) maak dit egter aan die begin van haar boek duidelik dat dit 'n misverstand is dat vrouens mans wil oorheers. Die doel met vrouestemreg is volgens haar on vrouens se lyding binne 'n manlik oorheersde samelewing te versag. Vrouens wil nie oorheers nie; hulle wil ophou ly. Hierdie misverstand tussen mans en vrouens kan, sê Du Toit, opgelos word deur gesonde verstand wanneer mans hulle in die posisie van lydende vrouens stel. Wanneer hulle vrouens se konteks sal verimerlik, sal hulle besef dat dit by vrouens nie om 
mag gaan nie, maar daarom dat hulle dit nie meer onder mans se mag kan uithou nie. Die manier waarop mans mag gebruik, meen Du Toit, veroorsaak dat dit met vrouens sleg gaan in die samelewing, in 'n konteks waarbinne hulle stemloos is en niks kan doen nie.

\section{Weduwees mag stem, maar nie ongetroude vrouens nie}

Die kommissie se (voor)laaste punte kondoneer stemreg aan weduwees en die lewer van sekere maatskaplike dienste deur ongetroude vrouens:

6. Hierdeur word nie uitgesluit nie, maar dit volg juis uit die bowestaande, dat waar die man as gesinshoof wegval, die vrou in sy posiesie intree en aanspraak het op al sy regte, ook die staatkundige.

7. Wat die maatskaplike posiesie van vroue aangaan, wat vir hulself ' $n$ broodwinning moet verskaf en dus selfstandig in die lewe optree, dis ' $n$ punt wat nadere oorweging verdien in verband met ons teenwoordige sosiale toestande. Voorsiening tot handhawing en verbetering van die privaatregtelike posiesie van sulke vroue, is deur voorgaande punte nie uitgesluit nie. Maar dit bepaal sig tot die terrein van die maatskaplike en raak nie die staatkundige lewe nie. Wederkerig kan die vrou naar haar bestemming op maatskaplike terrein haar onmisbare hulpe bied in sake soos die skool, die hospitaal, die Rooi Kruis en soveel meer (Handelinge van die Sinode, 1920:82).

Die eerste vyf punte van die kommissie se verslag beklemtoon dat getroude vrouens slegs ' $\mathrm{n}$ private posisie kan beklee, punt 6 laat weduwees toe om ook 'n staatkundige posisie te beklee en as gesinshoof te stem; punt 7 gee toe dat ongetroude vrouens, alhoewel hulle nie mag stem nie, moontlik tog maatskaplike take kan uitvoer.

Du Toit (1921:140-141) vind weer eens dat die onderskeiding wat tussen weduwees en getroude vrouens gemaak word, asook tussen vrouens se private, maatskaplike en staatkundige lewe kunsinatig en 'il divorce of convenience is. Sy het 'n logiese probleem met die standpunt (in punt 5) dat getroude vrouens die swakkere vat is wat nie aan die ruwe politieke lewe opgeoffer moet word nie, maar "as haar man wegval (in punt 6) dan is sy 'n wonder van transformasie na siel en liggaam en kan alles doen wat haar man gedaan het, ook op staatkundig gebied".

Kuyper spreek in sy De eerepositie der vrouw (1914:18-20) sy kommer uit oor die geweldige groot aantal Nederlandse vrouens wat ongetroud bly. Hy blameer hiervoor die vrouens se weeldesug wat maak dat hulle te duur is om mee te trou. Kuyper betreur die feit dat vrouens so uitgesluit word van hulle godgegewe ereposisie in die gesin waar hulle tot ware vervulling kan kom. Du Toit (1921:41), daarenteen, wys op die politieke en maatskaplike invloed wat 'surplusvrouens' gedurende die oorlog in Noorweë, Swede en Duitsland uitgeoefen het. Haar 
bekommernis gaan oor die feit dat mans hierdie politieke en maatskaplike insigte van vrouens - en sy identifiseer vrouens se maatskaplike met hulle politieke insigte - wil neutraliseer vanuit 'n posisie van bedreiging.

Binne die onderskeid wat Kuyper vir vrouens tussen private en politieke sfere maak, staan hy vrouens se privaatregtelike bevryding voor en keur hy hulle openbare vryheid af. Die onderskeid wat die kommissie van die GKSA ten opsigte van vrouens se rolle maak, is nie soos in Kuyper se denke slegs tweeledig nie; hulle ken drie soorte rolle aan vrouens toe, afhangende van hulle getroude status: 'n private rol vir getroude vrouens, 'n staatkundige rol vir weduwees, en 'n moontlike maatskaplike rol vir ongetroude vrouens

Du Toit (1921:34) verwerp hierdie onderskeidinge, en dan ook implisiet Kuyper se toegewing dat feminisme aanvaarbaar is wanneer dit op die privaatregtelike bevryding van vrouens gerig is. Volgens Du Toit (1921:33) gaan dit in die feminisme om alle vrouens se belange op alle gebiede:

So kort moontlik gesê is feminisme die handhawing van al 'n vrou haar belange in alle omstandighede, te alle tye. Vir 'n vrou moet dit beteken vir jou geslag te wees alles wat die mans nog altyd vir hulle syne was en van jou geslag te maak ' $n$ deel van die mensheid waarop jy trots kan wees, in elke geval om vir die minderbevoorregte van jou geslag, sowel as vir die sekse as 'n geheel, alle voorregte, alle openinge tot sukses, alle moontlike versagting van kwellings, alle verkrybare hulp in moeilikhede, te verkry ... (Du Toit, 1921:33)

Volgens Du Toit het die feminisme 'n sosiale agenda wat deur 'n politieke stem gehanteer moet word. Die sosiale program van die feminisme sluit in dieselfde opleiding vir meisies as vir seuns, die verandering van diskriminerende wetgewing sodat vrouens seggenskap oor hulle kinders kan hê, die afskaffing van wit slawehandel, staatsubsidie vir behoeftige moeders, en gelyke betaling vir gelyke werk (Du Toit, 1921:43).

\section{Samevatting}

In die voorafgaande is die sieninge van Abraham Kuyper, die 1920-kommissie van die sinode van die GKSA, en Marie du Toit oor vrouestemreg langs mekaar geplaas. Spesiale aandag is aan Du Toit se reaksie op die kommissie van die GKSA se Kuyperiaanse standpunte gegee. Du Toit betoog deurgaans dat die beginsels wat die bestryders van vrouestemreg uit die Bybel oor vrouens se natuur maak, in botsing met die alledaagse realiteite van vrouens is. Du Toit beskou dit as natuurlik

* dat vrouens deur middel van die stemreg lyding in hulle sosiale omstandighede verlig en 'n menswaardige posisie in die samelewing inneem; 
* dat vrouens volgens hulle persoonlike talente aan alle beroepe deelneem, ook aan die openbare lewe, en daarin lojaal aan en trots op hulle geslag is;

* dat vrouens indiwidue is wat hulleself en hulle sosiale denke op sterkte van hulle eie breinkrag definieer;

* dat vrouens nie tipes is nie maar mense binne bepaalde kontekste;

* dat vrouens die stemreg het onafhanklik van hulle getroude status.

\section{Bibliografie}

BRINK, E. 1990. Man-Made Women: Gender, Class and the Ideology of the Volksmoeder. ( $I n$ Walker, C., ed Women and Gender in South-Africa to 1945. Cape Town : David Philip. pp. 273-292)

BROWN, E. 1992. Die vraag na die invloed van Abraham Kuyper op ds S J. du Toit Referaat gelewer tydens Kuyperkongres, Potchefstroom, 4 September 1992

D'ASSONVILLE, V.E. 1977 Totius, profeet van die Mooirivier: 'n lewenskets van prof. $\mathrm{dr}$ J.D du Toit Kaapstad : Tafelberg.

DE BRUIJN, J 1987. Abraham Kuyper, leven en werk in beeld Amsterdam : Historisch Documentatiecentrum

DU TOIT, M.M 1921 Vrou en feminist, of Iets oor die vrouevraagstuk Bloemfontein Nasionale Pers.

GEREFORMEERDE KERKE IN SUID-AFRIKA 1920. Handelinge van die Sinode

GERRITSMA, N 1987. Vrouwen achter's theeblad vandaan Gereformeerde denken over vrouwen, 1920-1940. (In Jaarboek voor de geschiedenis van de Gereformeerde Kerken in Nederland 6. Kampen : Kok pp 78-95)

KUYPER, A 1914. De eerepositie der vrouw Kampen : Kok

MANENSCHIJN, G 1987. De onbewustheid van weleer (In Geel, J red Moeder de vrouw en God de Vader: een moeizame relatie Amsterdam : VU pp 13-35.)

NABER, JW A 1937 Eerste proeve van een chronologisch overzicht van de geschiedenis der vrouwenbeweging in Nederland. (In De eerste feministische golf Jaarboek voor Vrouwengeschiedenis 6 1985. Nijmegen : SUN. pp 189-201)

POSTMA, W, 1918. Die boervrouw, moeder van haar volk. Bloemfontein : Nasionale Pers

SMEENK, C. 1937 De sociale denkbeelden van dr A Kuyper. Rotterdam, Utrecht Libertas

STOCKENSTRÖM, E 1921 . Die vrou in die geskiedenis van die Hollands-Afrikaanse volk 'n Beknopte oorsig van die rol wat die vrou in die geskiedenis van Suid-Afrika gespeel het in die 350 jaar tussen 1568 en 1918 Stellenbosch Pro Ecclesia

STOCKENSTRÖM, E 1944 Geskiedenis van die vrouebeweging en die vrouestemreg in Suid-Afrika tot 1930 Stellenbosch s n

WALKER, C. 1990. The Women's Suffrage Movement. The Politics of Gender, Race and Class (In Walker, C, ed Women and Gender in South Africa to 1945 Cape Town : David Philip pp 313-345)

VAN WERINGH, $\boldsymbol{J} 1967$ Het maatschappijbeeld van Abraham Kuyper Assen : Van Gorcum 